\title{
¿Por qué el fin del arte concierne al arte en general? Una explicación de la modernidad del arte desde Hegel contra Hegel'
}

Georg W. Bertram²

Freie Universität Berlin

Para los filósofos siempre ha sido evidente que, en algún momento, el arte llega a un fin. Como es bien sabido, Platón critica a los poetas por desviarse de la verdad. Desde la perspectiva de Platón, el arte finaliza cuando uno arriba a la verdad y muchos filósofos siguen suscribiendo este punto de vista. La concepción filosófica más prominente del fin del arte fue propuesta por Hegel, quien explícitamente manifestó que, en la época en que vivía, el arte había llegado a su fin (Hegel I975:I I). Arthur Danto seguía a Hegel al declarar que el estatus del arte había cambiado significativamente en la modernidad (Danto 1998). Se podría mencionar también a Nietzsche y a Adorno, con sus diferentes versiones de, por un lado, la concepción del fin socrático del arte (Nietzsche 1999) o, por otro lado, de una "desestetización del arte" (Adorno 2002:16). Este breve listado debería bastar para recordarnos que la idea del fin del arte está muy extendida. Pero ¿qué significa dicha idea? ¿Ha de ser entendida como una afirmación histórica? En lo que sigue, argüiré que la idea del fin del arte está equivocada si se la entiende de modo histórico. Debe ser concebida, más bien, como una afirmación sistemática. Sostendré que el fin del arte se hace patente en la posibilidad del fracaso inherente a cada obra.

I Publicado originalmente como "Why does the end of art matter for art in general? Explaining the modernity of art with Hegel against Hegel". En: Morte dell'arte e rinascita dell'immagine. Saggi in onore di Federico Vercellone, eds. Alessandro Bertinetto y Gianluca Garelli. Canterano: Aracne, 2017, 19-29. Copyright 2017 by Georg Bertram. georg.bertram@fu-berlin.de 2 GeorgW. Bertram es profesor e investigador del Institut für Philosophie en Freie Universität Berlin. Sus principales áreas de investigación son la filosofía del lenguaje, teoría del conocimiento, estética e idealismo alemán -en particular la filosofía de Hegel. 
El siguiente artículo tiene cuatro partes. En el transcurso del mismo, desarrollaré siete tesis con la esperanza de que con ello mi argumento resulte más accesible. En la primera parte, analizaré los que, a mi parecer, son los aspectos más importantes de la noción hegeliana del fin del arte. La segunda parte argüirá que el fin del arte, entendido en sentido hegeliano, es de importancia para cada obra de arte. A continuación, abordaré la pregunta respecto de cómo debemos entender la concepción hegeliana de la forma clásica del arte. Hegel sostiene que el fin del arte no es relevante para el arte en su forma clásica. ¿Qué deberíamos pensar sobre esto? Finalmente, en la cuarta parte, ofreceré algunas reflexiones sobre la importancia que el fin del arte tiene para nuestra recepción de obras artísticas individuales. Sostendré, primero, que la crítica de arte es un medio que constantemente nos vuelve conscientes del fin del arte $y$, en segundo lugar, que el fin del arte no debe ser entendido como si fuese algo simplemente inmanente al desarrollo interno del arte como una práctica aislada, sino que está, por el contrario, vinculado con la posición del arte en la sociedad.

\section{§ 1. La noción de Hegel del fin del arte}

Hegel afirma que el arte alcanzó su cúspide en su forma clásica (Hegel 1975: 517). Para entender el sentido de esta afirmación, tenemos que entender cómo concibe Hegel la forma clásica del arte. En su forma clásica, el arte está determinado por su figura sensorial-material. Su forma paradigmática es, por supuesto, la escultura. Según Hegel, el contenido de la escultura es completamente inseparable de su presentación sensorial-material. La tesis que subyace a esta concepción del arte clásico es la idea de que la obra de arte les habla a sus destinatarios por sí misma, sin exigir de ellos ningún tipo de interpretación. La forma que el artista ha dado al material captura el contenido de la obra de una manera ideal. En otras palabras, los destinatarios son capaces de comprender el contenido de la obra simplemente captando su figura sensorial-material. Así, la forma clásica del arte es la etapa en la que la eficacia del arte resulta completamente autocontenida. En una palabra, en la forma clásica del arte, los fundamentos del arte son evidentes por sí mismos.

Esta caracterización de la forma clásica del arte puede ayudarnos a entender la noción de fin del arte propuesta por Hegel. La forma clásica llega a su fin 
en el momento en que los fundamentos de la obra de arte dejan de ser evidentes por sí mismos. Esto último es propio de la forma romántica del arte $y$, en especial, del arte posterior a esta forma, el cual puede ser llamado arte después del fin del arte o-en breve-arte moderno. El fin de la forma clásica del arte ha de ser entendido como el fin del arte en el sentido de que representa el momento en que los fundamentos del arte dejan de ser evidentes por sí mismos. A la luz de estas reflexiones, creo que la noción hegeliana del fin del arte podría resumirse de la siguiente manera:

(I) Según Hegel, la modernidad es la etapa en la que los fundamentos del arte ya no son evidentes por sí mismos ${ }^{3}$.

La explicación de la noción de fin del arte ofrecida por Hegel hace referencia al cenit del arte. El cenit del arte es el punto en el que el arte constituye la práctica más importante a través de la cual una comunidad media su autocomprensión. Y, por consiguiente, el arte cae de este cenit una vez que pierde su estatus de práctica central a través de la cual una comunidad media su autocomprensión. ¿Qué nos dice todo esto acerca del arte después del fin del arte? Dos puntos parecen ser de particular importancia. Primero, incluso después de su fin, el arte sigue siendo una forma mediante la cual una comunidad se comprende a sí misma -simplemente pierde su estatus como la forma más importante de autorreflexión. En segundo lugar, el arte después del fin del arte deja de ser eficaz por sí mismo. Las obras de arte pierden su capacidad para ser comprendidas por sí mismas sin una interpretación adicional. Permítaseme elaborar un poco más estos puntos.

Según Hegel, el arte es una forma del espíritu absoluto. Esto significa que, tomado como un todo, el arte es un medio por el cual una comunidad reflexiona sobre sus propias normas y prácticas normativas (Pinkard 1994: 22Iss). El arte preserva esta función a través de todas sus etapas. Así, el fin del arte marca un giro en el modo como se realiza esta función. Para comprender el sentido de este giro, podemos plantear la siguiente pregunta: ¿de qué maneras las obras de arte no-clásicas o modernas ocasionan una reflexión sobre las normas y prácticas normativas de una comunidad? Una respuesta inicial podría ser la

3 Para una interpretación distinta de la comprensión hegeliana de la modernidad del arte, véase Pippin 2014. 
siguiente: lo hacen poniéndose a sí mismas en cuestión. Es decir, si la eficacia de una obra de arte deja de darse por sentada, entonces, la obra tiene que desarrollar desde cero el modo en que el arte en general realiza la función mencionada. Cada obra de arte tiene que plantear la pregunta acerca de cómo ella misma motiva la reflexión sobre las normas y prácticas normativas de una comunidad:

(2) En el estado en que los fundamentos del arte dejan de ser evidentes por sí mismos, las obras de arte tienen que reinventar continuamente lo que el arte es.

El arte después del fin del arte va a desarrollarse de maneras que no son determinadas por la condiciones específicas de las sociedades particulares. Va a desarrollarse de maneras imprevisibles. Pareciera que Hegel estuviese intentando decir que, tras su fin, el arte pierde su potencial para cumplir su función esencial. Pero esto no es lo que Hegel está diciendo. Entre otras cosas, él afirma que el fin del arte, en cierto sentido, libera al arte. La mejor manera de explicar en qué consiste esta libertad es decir que cada obra artística tiene que reinventar lo que el arte es.

¿Cómo establecen las obras de arte por sí mismas lo que es el arte? Lo hacen tomando una forma artística específica; por ejemplo, un cuarteto de cuerdas. Al componer su primer cuarteto de cuerdas, alguien como Brahms lucha con el modo en que la forma del cuarteto de cuerdas había sido interpretada por, digamos, Schumann y Schubert. Brahms busca encontrar una nueva interpretación de la forma misma en cuestión. De este modo, la forma del cuarteto de cuerdas es reinventada en cierto sentido. Así, el arte moderno es definido por una lucha constante. Cada obra de arte tiene que encontrar su lugar en el ámbito del arte y tiene que luchar para tener éxito reinventando el arte de un modo específico. Esta lucha es un resultado de la pérdida de los fundamentos evidentes del arte. En otras palabras, la lucha de las obras artísticas por reinventar lo que el arte es constituye precisamente la manera como el arte se vuelve libre. La noción de fin del arte de Hegel tiene que ser entendida como implicando estos dos aspectos: la pérdida de la evidencia y la consecución de la libertad. 


\section{$\S$ 2. La posibilidad del fracaso}

Esta apreciación de la idea del fin del arte tiene consecuencias importantes. La idea del fin del arte no es una tesis acerca del desarrollo histórico del arte en sus diversas formas. Más bien, se trata de una tesis acerca del modo en que cada obra de arte individual participa en una práctica esencialmente inestable. La inestabilidad de la práctica se manifiesta en cada obra artística en la posibilidad del fracaso:

(3) Cada obra de arte está determinada por el propósito de definir qué es el arte. Entonces, cada obra se confronta con la posibilidad del fracaso debido al propósito que ella misma establece.

La consecuencia más importante de la pérdida de los fundamentos evidentes es que cada obra de arte lleva la carga de tener que reinventar lo que el arte es. Dado que no hay un suelo estable al cual las obras individuales puedan recurrir, cada obra de arte tiene que poner en cuestión el arte como tal. He indicado cómo ocurre esto en referencia a formas específicas de arte, como el cuarteto de cuerdas. Pero la necesidad de reinventar el arte supone la posibilidad de que las obras de arte fallen en el propósito que les es propio. No hay nada que pueda garantizar que Brahms tendrá éxito en la reinvención de la idea del arte al componer su primer cuarteto de cuerdas.

Ahora bien, uno puede preguntarse cómo es posible tal fracaso dado el hecho de que en la modernidad el arte no posee una fundamentación estable. ¿Por qué la pérdida de fundamentos evidentes no implica simplemente que, en el arte moderno, todo vale? En mi opinión, es importante descartar la idea de que el arte moderno está definido por la arbitrariedad. La pérdida de fundamentos evidentes no conlleva una pérdida total de valores o significado. Más bien, implica una creciente toma de conciencia acerca de lo que el arte es (Danto 1986). Cada obra de arte es consciente de su propio estatus de ser arte. Así, las obras de arte moderno no están sometidas a criterios generales que dictaminen qué cuenta como arte y qué no. Más bien, se dan a sí mismas sus propios criterios para determinar qué significa ser arte. Estos criterios pueden verse como reglas que una obra de arte establece por su propia cuenta. 
Considérese, por ejemplo, la "ley de la forma" postulada por Adorno (2002, 3ss). La "ley de la forma" es el conjunto de reglas que determina cómo una obra de arte posiciona sus elementos en relación mutua. Estas reglas no tienen un carácter meramente formal. Son sustanciales en tanto buscan reinterpretar lo que es el arte. Deben ser entendidas como reglas vinculadas con el deseo de ofrecer una contribución valiosa al arte como práctica. De este modo, las obras de arte se confrontan de dos maneras con la posibilidad del fracaso. Primero, las reglas por las cuales la obra de arte estructura sus elementos pueden no ser artísticamente convincentes. Así, pueden conducir a lo kitsch o a la mera artesanía. En segundo lugar, aun cuando las reglas sean convincentes, puede que no sean implementadas de modo convincente. Una obra de arte puede fallar de acuerdo con sus propios estándares. En la modernidad, cada obra de arte se confronta con la posibilidad del fracaso. Considero que esta tesis es un aspecto esencial del concepto del fin del arte:

(4) La posibilidad del fracaso inherente a cada obra de arte hace patente el fin del arte.

He sostenido que, básicamente, la noción hegeliana del fin del arte articula la pérdida de los fundamentos evidentes por sí mismos del arte en la modernidad. Pero sería un error entender esta pérdida como restringida a un desarrollo o movimiento específicos en la historia del arte. Más bien, afecta a cada obra de arte individual. En la modernidad, ninguna obra artística puede reposar sobre fundamentos que la vuelvan eficaz en un sentido evidente. Así, cada obra de arte tiene que lidiar con esta pérdida de eficacia evidente de un modo u otro. Esta afirmación puede glosarse con la noción de que cada obra de arte se refiere al fin del arte. Si cada obra de arte se propone reinventar lo que el arte es, entonces, cada obra tiene que lidiar con su propia posibilidad de fracaso.

¿Cómo incide esto sobre el modo en que entendemos el fin del arte? El fin del arte es la propia autoconciencia del arte de no estar garantizado por un fundamento estable. Así, el fin del arte debe ser entendido como algo que es productivo para el arte como tal; es decir, precisamente esta falta de fundamentos evidentes por símismos despliega nuevas posibilidades artísticas. Sería un malentendido tomar la noción del fin del arte como si implicase que el arte ha perdido su habilidad para hacer una contribución importante a la sociedad. Se trata de lo contrario: con el fin del arte y la conciencia de la 
posibilidad del fracaso, el arte gana el potencial para dar nuevos impulsos al desarrollo de la sociedad. Esto no quiere decir que en la modernidad cada obra de arte sea exitosa y productiva. Pero, al contener el fin del arte en sí misma, cada obra está compelida a lidiar con la posibilidad del fracaso y a desarrollar, así, nuevas formas y reglas en un intento por preservar su propia eficacia y llevar a cabo exitosamente su objetivo de reinventar el arte como tal. En este sentido, el fin del arte concierne al arte en general.

\section{§ 3. ¿Por qué Hegel favorece la forma clásica del arte?}

La tesis de que el fin del arte concierne al arte en general parece contradecir el hecho de que Hegel prefiera la forma clásica del arte a la forma moderna del mismo. ¿Cómo podemos pensar la concepción defendida por Hegel de la forma clásica dentro del marco desarrollado hasta este punto? ¿Qué debemos hacer con la concepción hegeliana de la forma clásica del arte? Creo que deberíamos entenderla como una señal de que Hegel es consciente de la posibilidad del fracaso inherente al arte.

(5) Al establecer que la forma clásica constituye la forma más alta de arte, Hegel busca inmunizar al arte frente a la posibilidad del fracaso.

¿Por qué tantas filosofías del arte se apegan a la idea de un fin histórico (muerte) del arte si este, de hecho, no se termina (Geulen 2006)? Me parece que la comprensión del fin del arte que tiene Hegel es la que más se acerca a responder satisfactoriamente esta pregunta, pues indudablemente él era consciente de que el arte mantenía una función sumamente vital incluso después de su fin putativo. En sus lecciones sobre estética, Hegel demuestra una buena comprensión del arte de su tiempo - del arte tras el fin del arte. ¿Por qué entonces Hegel no explica el arte como una práctica interminable -como una práctica que se desarrolla sin fin?

Quizá encontremos una respuesta a este interrogante si pensamos en algunos de los aspectos centrales de la noción del fin del arte sobre los que he llamado la atención en la primera parte del presente texto: a través de su fin, el arte pierde sus fundamentos evidentes $y$, con esta pérdida, se vuelve libre. La libertad en cuestión debe haberle parecido peligrosa a Hegel. En la 
modernidad, el arte es capaz de desarrollarse a sí mismo de maneras que no pueden ser controladas. En una situación en la que el significado del arte ya no es evidente por sí mismo, el arte no puede restringirse a normas específicas, una tradición específica o algo similar. Me parece que Hegel no estaba preparado para aceptar la libertad que él consideraba característica del arte en su forma moderna. De esta manera, Hegel garantiza la evidencia de la eficacia del arte mediante la concepción de la forma clásica del arte, incluso si esta evidencia solo puede encontrarse en el pasado del arte.

Pero si se toma en serio las explicaciones de Hegel, es necesario considerar esta firme fundamentación como una ficción. El arte ha sido siempre una práctica inestable. Piénsese en las famosas competiciones entre pintores en la antigüedad, o en las disputas entre las artes conocidas como paragone. En disputas como estas, el arte se muestra a sí mismo como una práctica cuyos fundamentos y eficacia no resultan evidentes en ningún sentido, dejando en claro que se trata de una forma de práctica intrínsecamente ligada a una lucha. Hegel seguramente sabía esto. Pero quería permitirse pensar el arte como una práctica capaz, al menos en una época, de llegar al punto en que sus fundamentos sean evidentes por sí mismos.

\section{§ 4. La posibilidad del fracaso del arte y la crítica del arte}

Hasta ahora he explicado las maneras en que las obras de arte se confrontan con la posibilidad del fracaso. Sin embargo, mis explicaciones pueden haber sugerido que el éxito o el fracaso es algo que las obras de arte logran por sí mismas. Pero afirmar esto sería terriblemente engañoso. Las obras de arte no logran nada por sí mismas. Por el contrario, lo que una obra de arte logra como novela, cuarteto de cuerdas, performance o de otra manera está ligado siempre con la sociedad en que la obra es producida o recibida. Así, la recepción de una obra de arte es un aspecto esencial del posible fracaso o éxito de la obra. La siguiente tesis puede ofrecer una idea del significado que el fin del arte tiene para nuestras prácticas de recepción:

(6) La recepción de las obras de arte está determinada por la evaluación realizada por el receptor sobre si una obra de arte tiene éxito o fracasa 
con respecto a la redefinición del arte propuesta por la obra misma. De esta manera, cada receptor practica la crítica de arte.

La interacción con una obra de arte implica, entre otras cosas, que el receptor lleve a cabo una contemplación intensa de las estructuras y reglas inmanentes a la obra. Así, parecería que los receptores se entregasen, simplemente sumergiéndose en lo que la obra les ofrece. Pero esto solo es parcialmente cierto. Pese a que los receptores reflexionan sobre las estructuras y reglas formales de las obras de arte, también practican actividades críticas. Piénsese en alguien leyendo una novela y contándosela a un amigo. $O$ piénsese en la gente saliendo del cine después de una película y discutiendo lo que acaba de ver. Tales reacciones son comunes y deben ser entendidas como prácticas evaluativas (Carroll 2009, I53ss). Nuestras evaluaciones de obras de arte asumen muchas formas: desde breves conversaciones mientras leemos una novela hasta largas discusiones después de una película, entradas de blogs, interpretaciones en el marco de la investigación artística y -finalmenteinterpretaciones dentro de la crítica de arte en sentido estricto. En todas estas formas, los receptores articulan aquello que perciben como el éxito o el fracaso de una obra en particular y las razones por las que piensan que la obra tiene éxito o fracasa.

Estas prácticas evaluativas muestran que nuestra recepción del arte está ligada a nuestra conciencia de la posibilidad del fracaso de las obras de arte. Al interpretar una obra de arte, los receptores toman en cuenta las maneras en que la obra de arte trata de re-interpretar lo que el arte es. Es decir, toman en consideración el hecho de que la obra de arte, de manera independiente y por sí misma, articula una comprensión específica o incluso singular de lo que es el arte. Así, los receptores tienen en cuenta que no hay una medida común contra la cual la obra de arte pueda ser contrastada. De esta manera, los receptores participan en la configuración de la relación que una obra de arte específica tiene con el fin del arte. Plantean preguntas en torno a los estándares que una obra de arte pone para sí misma y se preguntan si satisface o no dichos estándares.

Pero, al entrar en contacto con una obra de arte, los receptores no solo interactúan con la obra en cuestión. Ellos viven en un contexto específico, hacen ciertas cosas, tienen relaciones con otros y se entienden a sí mismos 
de una manera específica. Es importante, por ello, no reducir el alcance que tienen las interacciones de los receptores con las obras de arte a las meras interacciones con las obras mismas. Tales interacciones están condicionadas también por el contexto en que vive el receptor, sus prácticas cotidianas, su autocomprensión y muchos otros factores. Esto tiene consecuencias sobre el modo en que concebimos las evaluaciones que llevan a cabo los receptores con respecto a las obras artísticas:

(7) Las evaluaciones que los receptores realizan de las obras de arte no se ocupan solo de las obras mismas, sino que también se orientan a discernir los múltiples impulsos corporales, perceptuales, emocionales - conceptuales que una obra contiene en relación con las formas de práctica específicas de un contexto histórico-cultural particular.

Hegel presenta observaciones importantes respecto de cómo debemos concebir las evaluaciones que los receptores de las obras de arte realizan. Según Hegel, las obras de arte están insertadas en prácticas histórico-culturales y tienen el propósito de contribuir con estas prácticas. Es importante enfatizar el hecho de que las evaluaciones de obras de arte trazan conexiones entre las obras artísticas mismas y las prácticas cotidianas de los receptores. Los receptores, así, no solo entienden los estándares establecidos por la obra de arte como estándares orientados a una reinterpretación de lo que el arte es. También los entienden como orientados a contribuir con las otras prácticas cotidianas de los receptores. Esto se refleja en las evaluaciones de los receptores. Los receptores se preguntan si los impulsos de la obra de arte hacen una contribución valiosa a sus prácticas diarias y a su autocomprensión. La manera en que nuestras evaluaciones reflejan la posibilidad del fracaso inherente a una obra no está fundada en la idea del arte como tal (por la idea de l'art pour l'art). Más bien, se basa en la particular autocomprensión práctica de los seres humanos que interactúan con obras de arte.

Traducción de JOSIMAR CASTILLA 


\section{Bibliografía}

Adorno, T, 2002. Aesthetic Theory. Traducción al inglés de R. Hullot-Kentor. Londres: Continuum.

Carroll, N., 2009. On Criticism. Londres: Routledge.

Danto, A., 1986. "The End of Art". En: The Philosophical Disenfranchisement of Art. Nueva York: Columbia University Press, 8I-II5.

— 1998. "The End of Art: A Philosophical Defense”. History and Theory 37 (4), I27-I43.

Geulen, E., 2006. The End of Art. Readings in a Rumor after Hegel. Stanford: Stanford University Press.

Hegel, G. W. F., 1975. Aesthetics: Lectures on Fine Art. Traducción al inglés de T. M. Knox. Oxford: Clarendon.

Nietzsche, F., 1999. The Birth of Tragedy out of the Spirit of Music. En: The Birth of Tragedy and Other Writings, eds. R. Geuss y R. Speirs. Cambridge: Cambridge University Press, I-II6.

Pinkard, T., 1994. Hegel's Phenomenology: The Sociality of Reason. Cambridge: Cambridge University Press.

Pippin, R. B., 20l4. After the Beautiful: Hegel and the Philosophy of Pictorial Modernism. Chicago: University of Chicago Press. 